\title{
A PESQUISA-AÇÃO COLABORATIVO-CRÍTICA COMO PERSPECTIVA TEÓRICO-METODOLÓGICA: PRODUÇÃO DE CONHECIMENTO E FORMAÇÃO-AUTOFORMAÇÃO EM CONTEXTO
}

\author{
Edson Pantaleão ${ }^{1}$ \\ Reginaldo Celio Sobrinho ${ }^{2}$ \\ Nubia Rosetti do Nascimento Gomes ${ }^{3}$ iD
}

\begin{abstract}
Resumo
Objetivamos estimular o conhecimento e o debate sobre as contribuições que a pesquisa-ação colaborativo-crítica pode trazer para o desenvolvimento de investigações sobre diferentes temas pertinentes do campo educacional. No cumprimento desse propósito, sistematizamos reflexões sobre essa perspectiva investigativa, referenciando-nos especialmente na teoria da vida cotidiana desenvolvida por Agnes Heller $(1977$; 1992) e na teoria do conhecimento elaborada por Henri Lefebvre (1968; 1995). Encontramos nesses autores importantes indicativos para compreendermos como a dialética - esfera da vida cotidiana e não cotidiana da vida - se expressa nos modos de realizar a "escola para todos" nos anos recentes. Ademais, fundamentados na perspectiva desses autores no escopo da pesquisa-ação colaborativo-crítica, compreendemos o trabalho investigativo como uma possibilidade de promover processos contínuos de produção de conhecimento e formação-autoformação em contexto.
\end{abstract}

Palavras-chave: Pesquisa-ação colaborativo-crítica; Perspectiva teórico-metodológica; Pesquisa. Formação

\section{THE COLLABORATIVE CRITICAL ACTION RESEARCH AS A}

THEORETICAL-METHODOLOGICAL PERSPECTIVE: THE

\footnotetext{
1 Doutor em Educação, Professor do quadro permanente do Programa de Pós-graduação em Educação, Universidade Federal do Espírito Santo (PPGE/UFES). E-mail: edpantaleao@ hotmail.com

2 Doutor em Educação, professor do quadro permanente do Programa de Pós-graduação em Educação, Universidade Federal do Espírito Santo (PPGE/UFES. E-mail: reginaldo.celio@ufes.br

3 Mestre em Educação, Pedagoga do Sistema Municipal de Educação de Vitoria/ES. E-mail: nrosetti80@hotmail.com
} 


\title{
PRODUCTION OF KNOWLEDGE AND EDUCATION AND SELF- EDUCATION IN CONTEXT
}

\begin{abstract}
We aim at stimulating knowledge and the debate on the contributions that the collaborative critical action research can bring to the development of investigations on different pertinent topics of the educational field. In order to fulfill this purpose, we systematized reflections on this research perspective, referring especially to the theory of everyday life developed by Agnes Heller (1977; 1992) and in the theory of knowledge elaborated by Henri Lefebvre $(1968 ; 1995)$. We find in these authors important indications to understand how the dialectic in the sphere of everyday life and not everyday life - is expressed in ways of conducting "school for all" in recent years. In addition, based on the perspective of these authors in the scope of collaborative critical action research, we understand the investigative work as a possibility to promote continuous processes of production of knowledge and education/selfeducation in context.
\end{abstract}

Key words: Collaborative critical action research; Theoretical-methodological perspective. Research; Formation

\section{LA INVESTITA-ACCIÓN COLABORATIVO-CRÍTICA COMO PERSPECTIVA TEÓRICO-METODOLÓGICA: PRODUCCIÓN DE CONOCIMIENTO Y FORMACIÓN-AUTOFORMACIÓN EN CONTEXTO}

\begin{abstract}
Resumen
Objetivamos estimular el conocimiento y el debate sobre las contribuciones que la investigación-acción colaborativo-crítica puede traer para el desarrollo de investigaciones sobre diferentes temas relevantes del campo educativo. En el cumplimiento de este propósito, sistematizamos reflexiones sobre esa perspectiva investigativa, referenciándonos, especialmente, en la teoría de la vida cotidiana desarrollada por Agnes Heller (1977; 1992) y en la teoría del conocimiento elaborada por Henri Lefebvre (1968; 1995). Encontramos en esos autores importantes indicativos para comprender cómo la dialéctica - esfera de la vida
\end{abstract}


cotidiana y no cotidiana de la vida - se expresa en los modos de realizar la "escuela para todos" en los años recientes. Además, fundamentados en la perspectiva de esos autores en el ámbito de la investigación-acción colaborativo-crítica, comprendemos el trabajo investigativo como una posibilidad de promover procesos continuos de producción de conocimiento y formación-autoformación en contexto.

Palabras clave: Investigación-acción colaborativo-crítica; Perspectiva teórico-metodológica; Investigación. Formación

\section{INTRODUÇÃO}

Nas duas últimas décadas, temos presenciado, no Brasil, movimentos de reforma educacional direcionados para todos os níveis e modalidades de ensino. Indicativos desses movimentos se presentificam no processo de desconcentração da gestão da educação, nos discursos sobre autonomia da escola, na flexibilização do currículo, nos propósitos da "escola para todos", na importância de considerar as diferenças humanas e educar na diversidade. Tais reformas têm provocado a necessidade de mobilizar a instituição escolar para outra forma de pensar seu trabalho e seus modos de ação com os profissionais que nela atuam, bem como com os alunos e comunidade na qual está inserida e atua. Compartilhando dessa compreensão, Garcia (2006) e Michels (2006) destacam que, com as recentes reformas educacionais, a organização do trabalho pedagógico escolar tem sido foco de referência para pensar processos de formação de professores. Crescentemente as práticas pedagógicas e administrativas vêm constituindo-se como temática e/ou objeto de estudos nas pesquisas de estudos na área educacional.

Associados a essa perspectiva, os principais resultados dos estudos que desenvolvemos no âmbito do nosso grupo de pesquisa (MILANEZI, 2016; ZIVIANI, 2016) indicam a pertinência de as experiências vividas no contexto da escola comum serem consideradas na avaliação das políticas e das propostas educativas que vêm sendo implementadas. Ademais, têm apontado a necessidade de maior aproximação entre as universidades e o contexto escolar, tornando profícuos o debate e o estudo sobre questões que preocupam tanto aqueles que se dedicam à sistematização e ao aprofundamento do conhecimento educacional quanto aqueles que, em contexto, cotidianamente enfrentam os diferentes desafiados e dilemas que marcam e narram os processos de ensinar e aprender. Esse indicativo alia-se à nossa compreensão de que, nas sociedades recentes, a escola se configura como lócus privilegiado 
de formação humana, um importante espaço de aprendizagens, tanto para os alunos quanto para os profissionais que nela atuam.

De fato, no espaço escolar acontecem diferentes processos de apropriação do legado do grupo cultural (sistemas de representação, formas de agir, de pensar, do controle das emoções, da construção de relações éticas). O conhecimento de si mesmo e o conhecimento do outro emergem desses processos interativos - intersubjetivos - que são possibilitados pela apropriação de linguagens - gestual, simbólica, falada, escrita (HELLER, 1992; VYGOTSKY, 1996).

Considerando a escola como lócus privilegiado de formação humana, inúmeros desafios delineiam e instigam modos criativos de realizar estudos que tomam o seu cotidiano como espaço empírico de investigação. Assim é que, na área das Ciências Humanas e Sociais, diferentes pressupostos teóricos vêm subsidiando delineamentos metodológicos específicos que conjugam esforços, no sentido de ampliar e aprofundar o conhecimento social sobre o ato educativo-formativo e concomitantemente desencadear ações reflexivas e críticas no cotidiano escolar (ALARCÃO, 2004, p. 23).

Trabalhando nessa direção, temos compreendido que a investigação no campo educacional demanda, entre outros aspectos, a adoção de uma abordagem teóricometodológica que, durante a própria pesquisa, colabore na instituição de processos que possibilitem aos sujeitos envolvidos fazer leituras críticas sobre as situações e acontecimentos com os quais estão implicados. Em outros termos, o trabalho investigativo tem-se configurado para nós como uma possibilidade de promover processos contínuos de produção de conhecimento e formação-autoformação em contexto.

Nessa perspectiva reflexiva e crítica que assumimos, qualquer fenômeno que acontece no contexto investigatório tem uma dimensão objetiva - o conjunto de manifestações observáveis - e uma dimensão subjetiva - o significado que tem para os que o vivem (SACRISTÁN; GÓMEZ, 1998). De maneira alguma, essas dimensões se nos apresentam dissociadas. Elas são complementares e, nesse sentido, nos motivam para a consideração da indissociabilidade entre o político, o ideológico e o pedagógico ao longo do trabalho de pesquisa (JESUS, 2008). A evidente imbricação desses aspectos sustenta nossos argumentos relativos à necessidade de o trabalho de pesquisa se constituir em processo de formação e mudança em contexto.

Assim, estudando as relações que se estabelecem no interior da sala de aula em articulação com o contexto sociocultural mais amplo e trabalhando sob a perspectiva de que a formação do "Outro" implica trabalhar a autoformação, vimos adotando a pesquisa-ação 
colaborativo-crítica (JESUS, 2005; 2008) como uma importante referência teóricometodológica nas investigações desenvolvidas no âmbito do nosso grupo de pesquisa.

Tendo por objetivo estimular o conhecimento e o debate sobre as contribuições que a pesquisa-ação colaborativo-crítica pode trazer para o desenvolvimento de investigações sobre diferentes temas pertinentes ao campo educacional, neste texto sistematizamos reflexões sobre essa perspectiva investigativa, referenciando-nos especialmente na teoria da vida cotidiana desenvolvida por Agnes Heller $(1977 ; 1992)$ e na teoria do conhecimento elaborada por Henri Lefebvre (1968; 1995).

Encontramos tanto em Heller quanto em Lefebvre argumentos para afirmarmos que estamos a um só tempo na vida cotidiana e fora dela. Uma vez que o nível cotidiano não é um campo fechado, liga-se a outros níveis da realidade social que produzem "atividades superiores" (LEFEBVRE, 1968). Essas atividades superiores, ou humano-genéricas, como denomina Heller $(1977$; 1992), distinguem-se daquelas da vida cotidiana, contudo delas não se desligam. É, pois, do cotidiano que emergem as relações, as ações, as escolhas e as decisões e se cumprem as "criações", aquelas que produzem homens e mulheres no curso de uma humanização. O conhecimento que se produz e se constrói nas esferas superiores da prática social deve mostrar sua "verdade" no cotidiano. Seja no âmbito da ciência, da arte, da filosofia ou da política, as criações precisam vir à vida cotidiana para verificar e "confirmar" a validade da criação (LEFEBVRE, 1968; HELLER, 1977).

De nossa perspectiva, essa elaboração apresenta importantes indicativos para compreendermos como a dialética - esfera da vida cotidiana e não cotidiana da vida - se expressa nos modos de realizar a "escola para todos" nos anos recentes. Tendo em vista que essa instituição e suas práticas formativo-educativas não surgem em si mesmas, são construções históricas mediadas pelos conhecimentos construídos nas relações sociais. Complementarmente, tal elaboração nos instiga e nos possibilita, no escopo da pesquisa-ação colaborativo-crítica, compreender a escola como espaço vivo, processual, com continuidade e descontinuidade no enredo da vida cotidiana.

\section{A PESQUISA-AÇÃO COLABORATIVO-CRÍTICA COMO PERSPECTIVA INVESTIGATIVA}

A pesquisa em ciências sociais e, no nosso caso específico, em educação deve ser entendida como modalidade que produz conhecimento, pois 
[...] se processa como resultado de articulação do lógico com o real, do teórico com o empírico. Não se reduz a um mero levantamento e exposição de fatos ou a uma coleção de dados. Estes precisam ser articulados mediante uma leitura teórica. Só a teoria pode caracterizar como científicos os dados empíricos. (SEVERINO, 2006, p. 70).

Então, ela só gera ciência se estiver articulada a esses dados por meio de uma “interpretação" teórica, entrelaçando o lógico com o real, do qual germina uma significação.

Para Severino (2006), quaisquer que sejam nossas diferentes concepções da subjetividade dos homens e da objetividade do mundo real, a "hermenêutica" do real pelo lógico se efetiva necessariamente pelo estabelecimento de um esquema relacional entre um sujeito e um objeto. Independentemente do paradigma epistemológico adotado, o conhecimento deve ser entendido como um processo de construção, e não como mera representação ou alguma poderosa instituição de suas possíveis essências.

\begin{abstract}
Na verdade, a representação mental com a qual 'operamos' nossos saberes concretos não constitui um ponto de partida, mas, sim, um ponto de chegada, ou seja, ela já é a resultante de um complexo processo de elaboração, de construção. Certamente, esse processo não pode nunca ser confundido com o processo de criação, como se o sujeito pudesse, de algum modo, fazer um objeto existir. O que se quer dizer é que, para se apreender um objeto como sendo significativo para nós, é preciso como que refazer a estrutura desse objeto, seja ele um objeto físico, simbólico ou imaginário. Esse é o modo humano de conhecer. (SEVERINO, 2006, p. 71).
\end{abstract}

É o conhecimento que orienta a existência e conduz a humanidade na história. Em vista disso, o homem particular é sedento por conhecer o mundo que o rodeia, os outros homens e a si mesmo. É o que movimenta suas "relações" na vida cotidiana. Essas não se apresentam de forma "transparente", é preciso interpretá-las para compreendê-las. A "aparência" e a "essência" dessas relações fenomênicas não coincidem necessariamente, embora uma revele elementos da outra. Manifesta-se aí a relação dialética da realidade, o que torna a ciência necessária (GOHN, 2005).

Nessa direção, compreendemos que:

O conhecimento (a razão que quer conhecer) não pode parar nesse imediato (nas sensações, nas primeiras impressões), com o qual se satisfaz frequentemente o senso comum. Deve ir mais longe, na convicção de que, por detrás do imediato, há uma outra coisa que, ao mesmo tempo, se dissimula e se expressa nesse imediato; que o imediato é apenas a constatação (ainda insuficiente e abstrata, nesse sentido) da existência da coisa; e que nós atingiremos "algo" mais real: o próprio ser, sua "essência". (LEFEBVRE, 1995, p. 216).

Portanto, o conhecimento parte do fenômeno para buscar a sua "razão de ser" e encontrar essa "razão de ser" na coisa em si, na essência. Contudo, esta, ao se objetivar, já não 
é mais a "essência pura", pois produz/germina outra essência. Esse é o movimento dialético que o conhecimento busca adentrar-se (LEFEBVRE, 1995).

Disso derivam, para Lefebvre (1995), certas regras do pensamento dialético, pois não devemos contentar-nos em apenas olhar ou mesmo em observar as coisas; precisamos, sim, "penetrar" ativamente nelas. "Deve-se buscar a lei não fora do fenômeno, mas nele, em seu lado ou aspecto universal. É preciso não esquecer de interrogar de novo o fenômeno, para assegurar-se de que nada importante foi omitido" (LEFEBVRE, 1995, p. 222).

Sendo assim, investigar um fenômeno implica saber o que o leva a se manifestar. Por que ele se manifesta? Como se manifesta? Quais “implicações" são desencadeadas nas suas manifestações?

Sobre isso, Gohn (2005) argumenta que o pensamento será científico quando não se contentar com a forma como o acontecimento se manifesta pela situação, mas o questiona, quando se constrói com base na investigação dos fatos reais. Nas palavras dessa autora, “é imprescindível que se analisem os elementos fundamentais da problemática, retornando à pergunta formulada como objeto inicial da investigação" (GOHN, 2005, p. 255), pois:

São várias as abstrações que temos de realizar para entender o real, para chegarmos ao chamado concreto histórico pleno de significados. Trata-se, portanto, de buscar as relações e os processos que são constitutivos dos acontecimentos que expliquem a natureza de seu movimento. (GOHN, 2005, p. 257).

Assim, o conhecimento envolve a busca dos elementos que constituem o "problema" à luz de um referencial teórico. Considerando que o "problema" não se apresenta de forma "transparente" e linear, mas acontece sempre permeado de complexas relações e mudanças, a pesquisa em ciências sociais deve desenvolver-se conforme as exigências dos seus acontecimentos, de acordo com o seu movimento e as relações sociais, econômicas, políticas e culturais envolvidas, pois a pesquisa não deve procurar revelar apenas o movimento presente, imediato dos fenômenos, mas procurar compreender como estes se reproduzem e se transformam nos próprios movimentos históricos (GOHN, 2005; NOSELLA; BUFFA, 2005).

Portanto, investigar o particular com um olhar dialético requer compreendê-lo nas suas relações mais globais/totais. Para Lefebvre (1968), uma análise crítico-dialética da realidade pressupõe considerar as relações dos aspectos micro e macrossociais., pois a vida cotidiana e a sociedade têm mútuas implicações. O conhecimento é, nesse sentido, prático, social e histórico, já que é constituído em torno de temas e objetos fenomênicos que se manifestam nos grupos sociais concretos com projetos de vida locais, mas relacionados aos aspectos sociais, econômicos, políticos e culturais globais. 
Nessa perspectiva, no campo educacional, entendemos que, para compreender a relação local-total, é primordial considerar o cotidiano escolar como ponto de partida. Num movimento dialético de investigação, não basta apenas registrar as representações dos sujeitos; elas podem expressar formas de ver e pensar, mas o pesquisador tem que ir além delas (GOHN, 2005).

É necessário localizar as falas e as representações no universo de valores daquelas personagens; buscar explicar as matrizes que organizam esses valores, os interesses que os condicionam, as estruturas econômicas e culturais que propiciam aquelas representações; quais negam e quais reafirmam a condição socioeconômica e cultural daquelas personagens; quais as culturas de resistência existentes, quais os jogos de linguagens e que tipo de comunicação elas estruturam. (GOHN, 2005, p. 270).

Corroborando esses argumentos, Jesus (2008, p. 1) nos alerta sobre o fato de que o pesquisador que se colocar em um espaço-tempo ético de instituir conhecimento sobre os/nos processos educacionais deve considerar que os fenômenos, em sua complexidade, apresentam modalidades diversas de expressão. Segundo a autora, há que se investir na compreensão da processualidade dos movimentos vividos. Focalizar as experiências e os diferentes sujeitos, abrindo espaço para o agir colaborativo, superando a descrição, a denúncia “[...] para articular projetos e utopias, construir alternativas de sentidos e de práticas, criar condições de pertencimento e de canais de expressividade" (JESUS, 2008, p. 1).

O trabalho investigativo que temos realizado no âmbito do nosso grupo de pesquisa vem assumindo essa perspectiva de investigação. Em colaboração com os sujeitos implicados na interpretação, na transformação e na (res)significação de "práticas pedagógicas inventadas" em contexto, não desenvolvemos uma investigação apenas sobre a educação, mas procuramos provocar, com os sujeitos, possibilidades para que o próprio processo, ao produzir conhecimentos, viabilize a transformação da prática educativa (SACRISTÁN; GÓMEZ, 1998; CARR; KEMMIS, 1988).

Ao assumirmos os princípios teórico-metodológicos da pesquisa-ação colaborativocrítica, concebemos o pesquisador como um colaborador dos sujeitos do cotidiano escolar. Nessa atitude de parceria, problematizamos aspectos do objeto estudo, empenhando-nos em dialogar permanentemente sobre os fatos e fenômenos que emergem como "problemas" no cotidiano, com vistas à intervenção e à transformação deles (CARR; KEMMIS, 1988).

Sabe-se que

\footnotetext{
${ }^{4}$ No escopo das investigações que desenvolvemos, utilizamos o termo "inventar" compreendendo-o como um processo possibilitado pelos conhecimentos construídos sobre a profissão e sobre o fazer pedagógico específico.
} 
A pesquisa-ação reconhece que o problema nasce, num contexto preciso, de um grupo em crise. O pesquisador não o provoca, mas constata-o, e seu papel consiste em ajudar a coletividade a determinar todos os detalhes mais cruciais ligados ao problema, por uma tomada de consciência dos atores do problema numa ação coletiva. (BARBIER, 2004, p. 54).

Nesses termos, o pesquisador, utilizando-se da abordagem crítica da ciência educativa, envolve os sujeitos participantes na interpretação e na exploração dos fatos emanados no cotidiano para compreendê-los e tentar resolvê-los (CARR; KEMMIS, 1988). É um processo e um movimento de fazer juntos, de dialogar, de propor, de construir, de instituir experiências e possibilidades que mobilizem e motivem o "Outro" (JESUS, 2008).

Esse movimento nos remete a uma questão de implicação, tanto do pesquisador quanto dos sujeitos envolvidos na pesquisa. Nos termos de Barbier (2004), implicação consiste num engajamento pessoal e coletivo, em que o "Eu" e o "Outro" se implicam mutuamente. Nesse sentido, a própria implicação é o fator construtivo inerente à ação e ao pensamento (HELLER, 1980). Ao compreendermos que a perspectiva da pesquisa-ação colaborativo-crítica (JESUS, 2005, 2008) nos possibilitaria tais processos de implicação e ao concebermos esse tipo de pesquisa como primordial na construção de processos críticos no contexto escolar, direcionamos nossas investigações recentes (MILANEZI, 2016; ZIVIANI, 2016).

Outro importante ponto de ancoragem de que nos utilizamos, ao assumirmos a pesquisaação colaborativo-crítica como referente teórico-metodológico, é a perspectiva de que, no movimento coletivo de investigação, pesquisadores e participantes da pesquisa produzem novos modos de implicação com a própria formação. Esse princípio nos aponta a possibilidade e a necessidade de, no curso investigativo da pesquisa-ação, constituir o "pesquisador coletivo" (BARBIER, 2004).

De acordo com Jesus (2008), o "pesquisador coletivo" é a "mola propulsora" dos processos grupais. Essa dimensão coletiva do/no processo investigativo, “[...] remete à pesquisa ativa de um grupo envolvido, ou seja, 'o pesquisador' necessita assumir a mediação grupal, como parte do desafio da dinâmica da pesquisa. [...] No pesquisador-coletivo, dá-se o processo de co-formação" (JESUS, 2008, p. 16). Isso requer do pesquisador uma capacidade de "escuta sensível", uma atitude ética de oferecer ao outro uma possibilidade de um encontro, de estabelecer com ele uma relação de totalidade em sua existência dinâmica (MEIRIEU, 2002; BARBIER, 2004). O processo de pesquisa, nessa perspectiva, desenvolvese como

[...] uma rede simbólica e dinâmica, construído pelo pesquisador coletivo a partir dos elementos interativos da realidade, aberto à mudança e, necessariamente, 
inscrito no tempo e espaço. Um processo repleto de incertezas, de modos de se constituir que não podem ser previstos a priori na sua forma ou sua natureza. (JESUS, 2008, p. 16).

A implementação dessa perspectiva teórico-metodológica em pesquisas no campo educacional nos tem levado a eleger a escola como espaço empírico de investigação. Conforme a temática ou a problematização orientadora da investigação empreendida, diferentes sujeitos e suas ações ganham centralidade em nossos estudos. Trabalhamos com equipes de gestão escolar, equipe técnica, professores, pais/familiares, estudantes de diferentes etapas e/ou modalidades e outros profissionais que atuam no cotidiano escolar. Vale destacar que a concepção de sujeito que assumimos em nossas investigações se pauta na perspectiva do materialismo histórico, pois consideramos os homens e as mulheres como sujeitos históricos e da história que, por meio do conhecimento, produzem e reproduzem processos sociais, bem como se constituem como sujeitos nesses processos.

Em linhas gerais, os processos da pesquisa-ação que desenvolvemos se organizam em fases/momentos não lineares que se interpenetraram (JESUS, 2005). Inicialmente, partindo de uma temática ou de uma problematização específica relacionada ao campo educacional, realizamos um movimento de aproximação ao campo e aos sujeitos da pesquisa. Nesse momento, negociamos e (re)construímos nossa intencionalidade investigativa, revisando nossos propósitos e delineando melhor nossa temática de pesquisa. Esse movimento inicial se realiza por meio de nossa inserção no cotidiano escolar como Observador Participante Ativo $(\mathrm{OPA})^{5}$. Nessa condição, procuramos descrever, compreender e analisar as ações e as relações dos sujeitos em suas práticas cotidianas. Para isso, participamos do cotidiano da escola nos seus diversos tempos e espaços.

Em outro momento específico da investigação, realizamos entrevistas individuais e/ou coletivas envolvendo os sujeitos da pesquisa. Essa ação nos ajuda a conhecer, com maior profundidade, as concepções de escola, de educação e de aprendizagem que orientam e fundamentam as práticas cotidianas da/na escola. Associados às entrevistas, via de regra, também estudamos diferentes documentos que narram e expressam a intencionalidade educativa da escola que focalizamos e/ou que nos permitem conhecer alguns aspectos e/ou peculiaridades da comunidade escolar.

Conforme vimos realizando no âmbito do nosso grupo de pesquisa, quando nos utilizamos da perspectiva teórico-metodológica da pesquisa-ação colaborativo-crítica, o

\footnotetext{
${ }^{5}$ OPA - Tipo de observação definida por Adler e Adler (1987, apud BARBIER, 2004, p. 126). Nesse processo de observação, "[...] o pesquisador tenta, por meio de um papel desempenhado no grupo, adquirir um status no interior do grupo ou da instituição que estuda. Ele está simultaneamente dentro e fora do grupo".
} 
momento de atuação em contexto, entendido como espaço-tempo de "fazer com", ganha absoluta pertinência. Nesse momento peculiar do/no processo de coleta e de produção de dados, buscamos construir "respostas" para questões e tensões que emergem no fluxo das relações que estabelecemos em contexto.

Considerando que a pesquisa-ação colaborativo-crítica se configura como uma investigação emancipatória, que vincula teorização educacional e prática à crítica (JESUS, 2008), nesse momento de atuação em contexto, os participantes do processo de investigação pesquisadores e outros sujeitos envolvidos - constituem o pesquisador coletivo e, por essa via, constroem individual e coletivamente novos/outros significados para os saberes que praticam.

Pela via do "pesquisador coletivo", os participantes da pesquisa entram em um processo de coformação construindo as estratégias de intervenção/ação. Assim é que, ao atuar em contexto, o pesquisador “[...] não é nem um agente de uma instituição, nem um ator de uma organização, nem indivíduo sem atribuição social; ao contrário, ele aceita eventualmente esses diferentes papéis em certos momentos de sua ação e de sua reflexão" (BARBIER, 2004, p. 19). Guardadas as tensões e os inúmeros desafios decorrentes desse tipo de imersão do pesquisador no cotidiano escolar, cumpre destacar que esse modo de participação e de atuação nos permite superar uma visão determinista/finalista e dogmática em que o "resultado" é encontrado antes mesmo do início da investigação; mais: o objeto pesquisado é concebido numa perspectiva eles.

De fato, na perspectiva teórico-metodológica da pesquisa-ação colaborativo-crítica, a imersão no contexto e o momento de "fazer com" são primordiais para o delineamento do objeto de pesquisa. Ademais, no escopo dessa perspectiva teórico-metodológica, o que estudamos e investigamos faz parte da nossa realidade; os indivíduos a que nos referimos em nossas descrições e análises são vistos e percebidos como pessoas semelhantes a nós. Nesse sentido, em meio às tensões, alimentamos crenças, valores, destituímos lugares, "revolucionamos", mas também participamos e legitimamos processos excludentes. Afinal, "a vida cotidiana é a vida de todo homem [...]" e "[...] é a vida do homem inteiro [...]"; assim, ele "[...] participa na vida cotidiana com todos os aspectos de sua individualidade, de sua personalidade [...]" (HELLER, 1992, p. 17). Nas relações estabelecidas na vida cotidiana, estão em jogo todos os nossos sentidos, sentimentos, emoções, capacidades intelectuais, habilidades manipulativas, paixões, ideias e ideologias.

Nossa trajetória pessoal e profissional e também nossa constituição como pesquisadores narram nosso envolvimento e nossas implicações na área da educação especial. Assim, 
finalizamos este item, destacando aspectos de alguns estudos que assumiram como delineamento teórico-metodológico a pesquisa-ação colaborativo-crítica, para discutir questões relacionadas à garantia de acesso e de permanência de estudantes com deficiência e/ou com transtornos globais do desenvolvimento ao ensino.

Entre as temáticas abordadas nesses estudos, notamos a preocupação com as práticas pedagógicas desenvolvidas em classes de ensino comum que contam com a matrícula de estudantes com deficiência e/ou com transtornos globais do desenvolvimento (VIEIRA, 2012; CORREIA, 2014; AGUIAR, 2015; MILANEZI, 2016; ZIVIANI, 2016). Também aparecem nos debates preocupações relativas ao atendimento educacional especializado, particularmente às atividades implementadas pelos professores especialistas durante $\mathrm{o}$ atendimento educacional especializado e a articulação dessas atividades ao trabalho que vem sendo realizado nas classes de ensino comum (NASCIMENTO, 2013; BORGES, 2014). As questões relativas à avaliação da aprendizagem (AGUIAR, 2015), formação e qualificação dos professores especialistas e dos profissionais que atuam no ensino comum também constituem foco de estudos apoiados nos pressupostos da pesquisa-ação colaborativo-crítica (VIEIRA, 2012; CORREIA, 2014; ZIVIANI, 2016).

No percurso investigativo, os autores se utilizam de questionários, de estudo de documentos da instituição escolar, de grupos focais, de observação, de entrevistas semiestruturadas e especialmente de intervenções nas classes de ensino comum, nos momentos destinados ao planejamento e à formação continuada de professores.

Coerentemente com os princípios da pesquisa-ação, a teoria crítica se configura como referencial mais recorrente nos trabalhos que se utilizam dessa perspectiva investigativa. Nesse sentido, observamos que os autores desenvolvem reflexões que objetivam potencializar melhorias no acesso e na permanência dos estudantes com deficiência e/ou com transtornos globais do desenvolvimento na escola de ensino comum.

Assim, as discussões empreendidas pelos autores indicam que muitas tensões vivenciadas no cotidiano escolar se vinculam à precariedade das condições de funcionamento da escola. Essa precariedade refere-se, por exemplo, ao processo de rotatividade de profissionais, à ausência de espaços sistemáticos de planejamento e de formação continuada no contexto escolar, à oferta insuficiente de recursos e de material pedagógico que qualifiquem o trabalho educativo desenvolvido com os estudantes. As análises dos autores também evidenciam questões afetas à formação inicial dos profissionais do ensino, à organização dos tempos e dos currículos escolares e à implementação da gestão democrática. 


\section{CONSIDERAÇÕES FINAIS}

Conforme destacamos, temos assumido os pressupostos da pesquisa-ação colaborativocrítica como possibilidade de acompanhar os movimentos da escola, considerando a dinâmica das relações que ali se estabelecem. A adoção dessa perspectiva investigativa vem possibilitando-nos realizar uma análise crítico-dialética da realidade escolar nos seus aspectos micro e macrossociais.

Nesse modo de análise e de compreensão da realidade escolar, temos encontrado em Heller (1977; 1992) e em Lefebvre (1968) elementos que justificam nossa perspectiva de que, no âmbito de uma reflexão sobre o cotidiano e no cotidiano, principalmente com base nas relações com os sujeitos que dele participam, poderemos compreender melhor as ações daqueles que se encontram confrontados dia após dia com os dilemas e desafios decorrentes de tantas tensões e restrições inerentes à vida de um estabelecimento escolar.

Não podemos perder de vista que, nas relações com o mundo social, novas aprendizagens são conquistadas. Sobre isso, Lefebvre (1995) argumenta que, na interação com o meio social e material, os homens adquirem conhecimentos e, para tal, necessitam utilizar alguns instrumentos que lhes possibilitem serem sujeitos ativos, capazes de modificar o seu meio de relações e a si mesmos. Temos encontrado na pesquisa-ação colaborativocrítica notáveis contribuições nessa direção.

A respeito dessa perspectiva teórico-metodológica, vale ainda considerar (e reiterar) a importância dos contatos cotidianos com os sujeitos que constituem o espaço escolar para o aprimoramento dos nossos olhares. Afinal, no escopo da pesquisa-ação colaborativo-crítica, a condição de pesquisador supõe não somente constatar "o problema", mas também colaborar com os sujeitos em uma análise crítica da situação-problema, planejando ações coletivas e compartilhadas (BARBIER, 2004).

Complementarmente, outro aspecto que consideramos pertinente ressaltar diz respeito à nossa implicação com o contexto, na condição de pesquisador. A abordagem teóricometodológica da pesquisa-ação colaborativo-crítica nos insere no fluxo das relações e das tensões que constituímos e vivenciamos com os "sujeitos da pesquisa". Assumindo uma perspectiva nós, ao longo das intervenções, partilhamos com "eles" as dúvidas, os conflitos e as ansiedades. Nesse processo de engajamento pessoal e coletivo, "Eu" implico o "Outro" e sou implicado por ele. Esse mergulho no fluxo histórico do grupo nos traz inevitavelmente implicações com o/no contexto. Esse é um desafio, nada desprezível, que se propõe ao pesquisador que pretende contribuir para a ampliação e o aprofundamento do conhecimento 
social relativo ao ato educativo-formativo, sem perder de vista o desenvolvimento de ações reflexivas e críticas no cotidiano escolar, durante a própria pesquisa. Essa é, na nossa percepção, uma experiência e uma lição fundamental extraída da utilização da abordagem teórico-metodológica da pesquisa-ação colaborativo-crítica e pesquisas do campo educacional.

\section{REFERÊNCIAS}

AGUIAR, Ana Marta B. Calcanhar de Aquiles: a avaliação do aluno com deficiência intelectual no contexto escolar. 2015. 264 f. Tese (Doutorado em Educação) - Programa de Pós-Graduação em Educação, Universidade Federal do Espírito Santo, Vitória, 2015.

ALARCÃO, Isabel. Professores reflexivos em uma escola reflexiva. 3. ed. São Paulo: Cortez, 2004.

BARBIER, René. A pesquisa-ação. Brasília: Liber Livro Editora, 2004.

BORGES, Carline Santos. Atendimento Educacional Especializado e os processos de conhecimento na escola comum. 2014. 200 f. Dissertação (Mestrado em Educação) Programa de Pós-Graduação em Educação, Universidade Federal do Espírito Santo, Vitória, 2014.

CARR, W.; KEMMIS, S. Teoria crítica de la enseñanza: la investigación-acción en la formación del profesorado. Tradução de J. A. Bravo. Barcelona: Martinez Roca, 1988.

CORREIA, Vasti Gonçalves de Paula. Alunos com paralisia cerebral na escola: linguagem, comunicação alternativa e processos comunicativos. 2014. 287 f. Tese (Doutorado em Educação) - Programa de Pós-Graduação em Educação, Universidade Federal do Espírito Santo, Vitória, 2014.

GARCIA, Rosalba M. C. Políticas para a educação especial e as formas organizativas do trabalho pedagógico. Revista Brasileira de Educação Especial, Universidade Estadual Paulista. v. 12, n. 3, 2006. Marília: ABPEE/FFC-Unesp, 2006. DOI: 10.1590/S141365382006000300002 .

GOHN, Maria da Glória M. A pesquisa na produção do conhecimento: questões metodológicas. Eccos: Revista Científica, São Paulo, v. 7, n. 2, p. 253-274, jul./dez. 2005. ISSN 1517-1949. DOI: 10.5585/eccos.v7i2.416.

HELLER, Agnes. Sociologia de la vida cotidiana. Barcelona: Península, 1977.

Teoria de los sentimientos. Barcelona: Fontamara, 1980.

. O cotidiano e a história. 4. ed. Rio de Janeiro: Paz e terra, 1992. 
JESUS, Denise M. de. Formação continuada: construindo um diálogo entre teoria, prática, pesquisa e a educação inclusiva. In: JESUS, D. M. de.; BAPTISTA, C. R.; VICTOR, S. L. (Orgs.). Pesquisa e educação especial: mapeando produções. Vitória, ES: EDUFES, 2005.

- O que nos impulsiona a pensar a pesquisa-ação colaborativo-crítica como possibilidade de instituição de práticas educacionais mais inclusivas? In: BAPTISTA, Cláudio Roberto; CAIADO, Kátia Regina Moreno; JESUS, Denise Meyrelles de. (Org.). Educação Especial: diálogo e pluralidade. 1 ed. Porto Alegre: Editora Mediação, 2008, v. 1, p. 139-159.

LEFEBVRE, Henri. A vida cotidiana no mundo moderno. São Paulo: Ática, 1968.

Lógica formal, lógica dialética. 6. ed. Rio de Janeiro: Civilização Brasileira, 1995.

MEIRIEU, Philippe. A pedagogia entre o dizer e o fazer: a coragem de começar. Porto Alegre: Artmed, 2002.

MICHELS, Maria Helena. Gestão, formação docente e inclusão: eixos da reforma educacional brasileira que atribuem contornos à organização escolar. Revista brasileira de educação, Rio de Janeiro, v. 11, n. 33, set./dez. 2006. ISSN 1413-2478. DOI: 10.1590/S141324782006000300003.

MILANEZI, Tamille Correia de Miranda. Inter-relações surdos e ouvintes no processo de apropriação do conhecimento escolar por parte dos estudantes surdos. 2016. $164 \mathrm{f}$. Dissertação (Mestrado em Educação) - Programa de Pós-Graduação em Educação, Universidade Federal do Espírito Santo, Vitória, 2016.

NASCIMENTO, Alice Pilon do. Dialogando com as salas de aula comuns e o atendimento educacional especializado: possibilidades, movimentos e tensões. 2013. 227 f. Dissertação (Mestrado em Educação) - Programa de Pós-Graduação em Educação, Universidade Federal do Espírito Santo, Vitória, 2013.

NOSELLA, Paolo; BUFFA, Ester. As pesquisas sobre instituições escolares: o método dialético marxista de investigação. Eccos: Revista Científica, São Paulo, v. 7, n. 2, p. 351368, jul./dez. 2005. ISSN 1517-1949. DOI: 10.5585/Eccos. V7i2.421.

SACRISTÁN, José G.; GÓMEZ, A. I. Pérez. Compreender e transformar o ensino. 4. ed. Porto Alegre: Artmed, 1998.

SEVERINO, Antônio J. Pós-graduação e pesquisa: o processo de produção e de sistematização no campo educacional. In: BIANCHETTI, L.; MACHADO, A. M. N. (Orgs.). Bússola do Escrever: Desafios e Estratégias na Orientação e Escrita de Teses e Orientações 2. ed. - Florianópolis: Ed. UFSC; São Paulo: Cortez, 2006.

VIEIRA, Alexandro Braga. Currículo e Educação Especial: as ações da escola a partir dos diálogos cotidianos. 2012. 326 f. Tese (Doutorado em Educação) - Programa de PósGraduação em Educação, Universidade Federal do Espírito Santo, Vitória, 2012.

VYGOTSKY, Lev S. Teoria e método em psicologia. São Paulo: Martins Fontes, 1996. 
ZIVIANI. Mariza Carvalho Nascimento. Interdependência e colaboração em contextos escolares inclusivos. 2016. 174 f. Dissertação (Mestrado em Educação) - Dissertação (Mestrado em Educação) - Programa de Pós-Graduação em Educação, Universidade Federal do Espírito Santo, Vitória, 2016.

Data de recebimento: 27/09/2017

Data de aceite: $16 / 11 / 2017$ 